\title{
Influence of environmental boundary conditions on convective heat transfer coefficients of wall internal surface
}

\author{
Tullio de Rubeis ${ }^{1}$, Luca Evangelisti ${ }^{2}$, Claudia Guattari $^{2}$, Roberto De Lieto Vollaro ${ }^{2}$, \\ Francesco Asdrubali ${ }^{2}$, Dario Ambrosini ${ }^{1}$, and Domenica Paoletti ${ }^{1}$ \\ ${ }^{1}$ University of L'Aquila, Department of Industrial and Information Engineering and Economics \\ (DIIIE), Piazzale Pontieri 1, Monteluco di Roio, I 67100 L'Aquila, Italy \\ ${ }^{2}$ Roma TRE University, Department of Engineering, Via Vito Volterra 62, 00144 Rome, Italy
}

\begin{abstract}
In this study, convective heat transfer phenomena were investigated by means of a Guarded Hot Box (GHB) apparatus. An experimental setup characterized by air and surface temperature probes, and a hot-wire anemometer was used. Five small fans were installed in the metering chamber to generate a forced air flow characterized by different velocity values. So, the GHB was used for investigating the influence of different air speed values on internal convective coefficients. Considering horizontal heat fluxes, an internal convective coefficient values of 2.5 $\mathrm{W} / \mathrm{m} 2 \mathrm{~K}$ is reported in the Standard ISO 6946. However, no exhaustive description about this value is provided. The aim of this work is to experimentally determine the internal thermal surface resistance, quantifying how the convective heat transfer coefficient varies as air velocity changes.
\end{abstract}

\section{Introduction}

The building energy balance is strongly influenced by heat transmission losses through the opaque and transparent envelope. This, together with regulatory guidelines, justifies the growing effort to search for high thermal performance of insulating materials to reduce the thermal conductance of the envelope.

Generally, the thermal performance of the building envelope has a significant role. Thermal performance is measured in terms of heat loss and it is generally expressed in the construction industry as thermal resistance (R-value) or thermal transmittance (U-value) [1]. Thermal transmittance is the heat transfer rate through a building component, divided by the difference in temperature across that structure. On the contrary, thermal resistance is the converse of thermal transmittance, that is the capability of a building component to resist heat fluxes. The U-value calculations is mandatory when establishing construction strategies. Walls U-value is the most important thermophysical properties influencing the energy performance of a building [2,4]. The thermal transmittance of walls can be computed knowing the thermophysical properties of each layer of the wall, and it is usually obtained 
assuming surface thermal resistance values, internal and external, according to the standard ISO 6946 [5], depending on heat flux direction. The standard provides conventional surface resistances which can be applied for plane surfaces without detailed information on the boundary conditions. These values, that include convective and radiative thermal contributions, are obtained considering specific operating conditions. In particular, the convective heat transfer coefficients are given with different heat flux directions, but no detailed information on their determination are supplied.

The study related to the identification of suitable heat transfer coefficients becomes essential to obtain thermal transmittance values closer to the actual ones. Furthermore, a correct evaluation of heat transfer coefficients can be useful for calculating heat flows when indirect measurement approaches are applied. In fact, heat flows can be obtained indirectly, by means of temperature probes and setting an appropriate heat transfer coefficient. [6].

The aim of this work, whose preliminary results were discussed in [7], is to experimentally determine the internal thermal surface resistance of a wall and, specifically, the convective heat transfer coefficient, by means of a Guarded Hot Box, capable of imposing stable, controlled and repeatable thermal conditions. The experimental set up involves the use of fans, placed inside the metering chamber, with which to modify the boundary conditions (different air velocities), and then evaluate the effects on the convective heat transfer coefficient. Heat flux sensors, anemometer, and temperature probes (air and surface) allowed to obtain the necessary information to determine convective heat transfer coefficient that, together with radiative coefficient from ISO 6946, allows to determine the internal surface thermal resistance under different operating conditions.

\section{Materials and methods}

\subsection{Theoretical approach through ISO 6946}

The thermal resistance of walls can be computed applying the methodological approach reported in the standard ISO 6946. Considering a wall composition, the sum of the thermal resistances of each single layer $\left(R_{i}\right)$ and the surface thermal resistances of the inner side $\left(R_{s i}\right)$ and the outer side $\left(R_{s e}\right)$, is the total thermal resistance of the wall $(R)$. Starting from this, the following formula can be used:

$$
R=R_{s i}+\sum_{i} R_{i}+R_{s e}
$$

The convective $\left(h_{c}\right)$ and radiative $\left(h_{r}\right)$ heat transfer coefficients represent a key factor for calculating surface thermal resistances, because they are defined as the reciprocal of the sum of $h_{c}$ and $h_{r}$. Consequently, $R_{s}$ can be calculated using the following equation:

$$
R_{s}=\frac{1}{h_{c}+h_{r}}=\frac{1}{h_{t o t}}
$$

where $h_{\text {tot }}$ is total heat transfer coefficient. For horizontal heat fluxes, the Standard suggests an internal $R_{s}$ equal to $0.13 \mathrm{~m}^{2} \mathrm{~K} / \mathrm{W}$, whose value derives from a $h_{\text {tot }}$ of 7.69 $\mathrm{W} / \mathrm{m}^{2} \mathrm{~K}$. The Standard specifies that the convective part corresponds to a $h_{c}$ coefficient equal to $2.5 \mathrm{~W} / \mathrm{m}^{2} \mathrm{~K}$, not providing any additional detail about this value.

On the other hand, the radiative coefficient can be defined as:

$$
h_{r}=4 \varepsilon_{\mathrm{s}} \sigma T_{m}^{3}
$$


where $\varepsilon_{\mathrm{s}}$ is the emissivity of the wall surface, $\sigma$ is the Stefan-Boltzmann constant and $T_{m}$ is the average thermodynamic temperature of the surface and the surrounding surfaces. For horizontal heat fluxes, considering the mentioned total heat transfer coefficient of 7.69 $\mathrm{W} / \mathrm{m}^{2} \mathrm{~K}$, the radiative part is obtained considering an emissivity equal to 0.9 and a temperature of $20^{\circ} \mathrm{C}$. If, as said, $2.5 \mathrm{~W} / \mathrm{m}^{2} \mathrm{~K}$ represents the convective part, the radiative coefficient can be deduced, obtaining a value equal to $5.19 \mathrm{~W} / \mathrm{m}^{2} \mathrm{~K}$.

\subsection{Guarded Hot Box (GHB)}

Experimental measurements were performed using the hot box apparatus of the University of L'Aquila. It is well-known that Guarded Hot Box (GHB) is widely used to assess the thermal behavior of sample walls [8,9]. Inside GHBs specific thermal boundary conditions can be set. The GHB is characterized by one hot chamber and one cold chamber among which a sample wall is installed. On the hot side, a guard box surrounds a metering chamber. The internal thermal conditions are guaranteed through a control unit characterized by different slave units intended for the metering and guard boxes of the hot chamber, cold chamber, and sample wall $[10,11]$. The temperature probes installed in the GHB allow to determine, for the hot and cold side, the surface temperature of the wall, the radiant temperature, and the air temperatures. The positioning of sensors is in accordance with the standard ISO 8990 [12]. Figure 1 provides a simplified representation of the GHB.

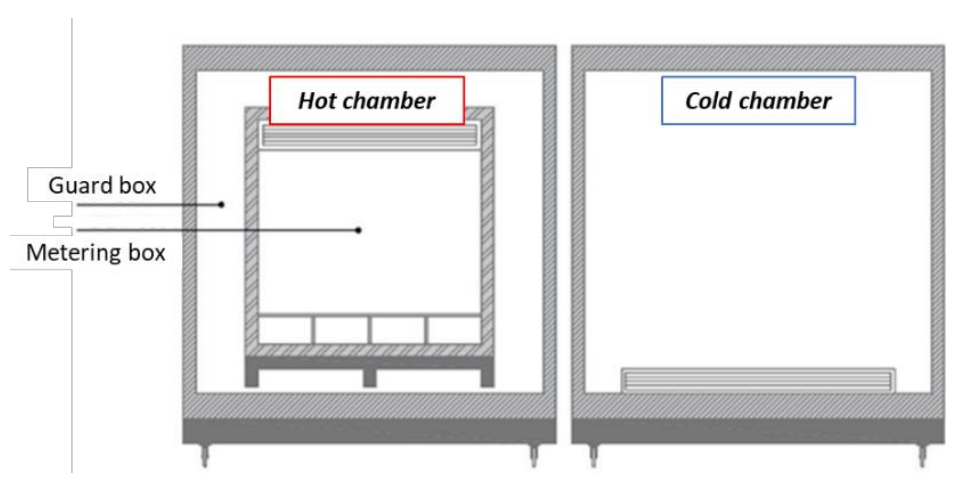

Fig. 1. Simplified view of the GHB.

The sample wall between the chambers is made of an X-lam panel structural member with double insulating layers, plastered on both sides, with a total thickness of $0.3 \mathrm{~m}$. The wall stratigraphy and the thermophysical properties of each layer are reported in Figure 2 and Table 1 , respectively.

The specific wall composition allows to obtain a high thermal performance, with a theoretical U-value equal to $0.176 \pm 0.03 \mathrm{~W} / \mathrm{m}^{2} \mathrm{~K}$. The wall is square in shape, with a side equal to $3 \mathrm{~m}$. Table 2 lists the technical data of the experimental setup installed in the GHB. 


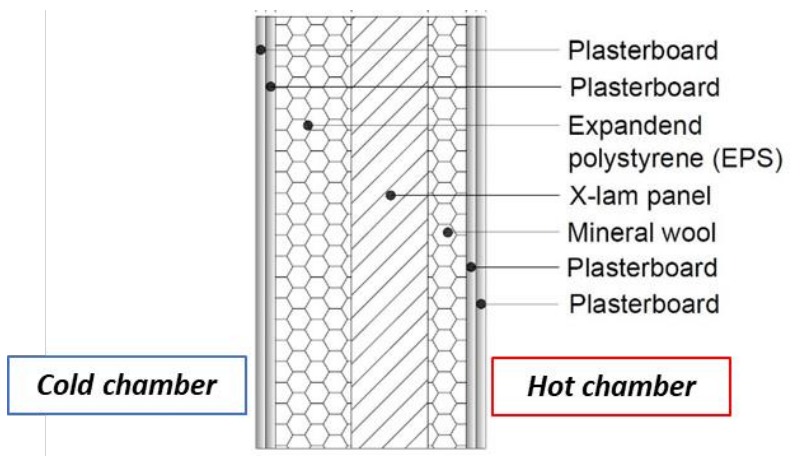

Fig. 2. Tested wall stratigraphy.

Table 1. Stratigraphy and thermal properties of the tested wall.

\begin{tabular}{|l|l|l|l|l|}
\hline Layer & $\begin{array}{l}\text { Thickness } \\
{[\mathrm{cm}]}\end{array}$ & $\begin{array}{l}\text { Thermal conductivity } \\
{\left[\mathrm{W} / \mathrm{m}^{2} \mathrm{~K}\right]}\end{array}$ & $\begin{array}{l}\text { Mass density } \\
{\left[\mathrm{kg} / \mathrm{m}^{3}\right]}\end{array}$ & $\begin{array}{l}\text { Specific heat capacity } \\
{[\mathrm{J} / \mathrm{kgK}]}\end{array}$ \\
\hline Cold side & - & - & - & - \\
\hline Plasterboard & 1.25 & 0.210 & 900 & 1000 \\
\hline Plasterboard & 1.25 & 0.210 & 900 & 1000 \\
\hline EPS and graphite & 10.00 & 0.031 & 32 & 1350 \\
\hline X-lam panel & 10.00 & 0.130 & 470 & 1600 \\
\hline Mineral wool & 5.00 & 0.039 & 135 & 850 \\
\hline Plasterboard & 1.25 & 0.210 & 900 & 1000 \\
\hline Plasterboard & 1.25 & 0.210 & 900 & 1000 \\
\hline Hot side & - & - & - & - \\
\hline
\end{tabular}

Table 2. Technical specifications of the measuring instruments.

\begin{tabular}{|l|l|l|l|}
\hline Sensor & Type & Measuring range & Resolution \\
\hline $\begin{array}{l}\text { Heat flow meter } \\
\text { sensor }\end{array}$ & Hukseflux HFP01 & -2000 to $2000 \mathrm{~W} / \mathrm{m}^{2}$ & $60 \times 10-6 \mathrm{~V} /\left(\mathrm{W} / \mathrm{m}^{2}\right)$ \\
\hline $\begin{array}{l}\text { Surface } \\
\text { temperature } \\
\text { probes }\end{array}$ & LSI Lastem EST124-Pt100 & -50 to $+70{ }^{\circ} \mathrm{C}$ & $0.01{ }^{\circ} \mathrm{C}$ \\
\hline $\begin{array}{l}\text { Air temperature } \\
\text { probes }\end{array}$ & Maxim Integrated DS18B20 & -55 to $+125^{\circ} \mathrm{C}$ & $0.0625^{\circ} \mathrm{C}$ \\
\hline $\begin{array}{l}\text { Hot-wire } \\
\text { anemometer }\end{array}$ & LSI Lastem ESV107 & 0.01 to $20 \mathrm{~m} / \mathrm{s}$ & $0.01 \mathrm{~m} / \mathrm{s}$ \\
\hline Datalogger & LSI Lastem M-Log ELO008 & -300 to $+1200 \mathrm{mV}$ & $40 \mu \mathrm{V}$ \\
\hline
\end{tabular}

\subsection{Methodology}

Once the steady state conditions in the hot box were reached, the following methodological approach was applied aiming to quantify how the convective heat transfer coefficient varies as air speed changes. Considering the inner surface of a wall, it is known that the Newton's law of cooling allows to quantify the convective heat flux transferred between air and wall surface. So, the following formula can be used: 


$$
q_{c, i}=h_{c, i}\left(T_{s i}-T_{a}\right)
$$

where $q_{c, i}$ is the internal heat flux, $h_{c, i}$ is the internal heat transfer coefficient, $T_{s i}$ is the temperature of the inner side of the wall and $T_{a}$ is the indoor air temperature. In particular, $h_{c, i}$ can be obtained by applying the approach based on the analysis of the dimensionless parameters. Grashof $(G r)$ and Reynolds $(R e)$ numbers regulate natural and forced convection. Richardson number is usually known in building science applications as Archimedes ( $A r)$ number [13]. $A r$ verifies the relative relevance of buoyancy and inertial forces and it can be defined as follows:

$$
A r=\frac{G r}{R e^{2}}
$$

Natural or forced convection can be identified in function of the conditions listed in Table 3.

Table 3. Type of convection as a function of the $A r$ number.

\begin{tabular}{|c|c|}
\hline Condition & Convection type \\
\hline$A r \gg 10$ & Natural \\
\hline $0.7<A r<10$ & Mixed \\
\hline$A r \ll 0.7$ & Forced \\
\hline
\end{tabular}

Under natural convection conditions, the $h_{c}$ coefficient can be found through the Nusselt $\mathrm{Nu}$ ) number which, in turn, can be defined in function of the Rayleigh $(R a)$ number:

$$
N u=\frac{h_{c} L}{\lambda}=A \cdot R a^{b}
$$

where $L$ is the characteristic geometrical length, $\lambda$ is the thermal conductivity of the fluid (in this case the fluid is air), and $A$ and $b$ are two constants depending on the geometric characteristics and the temperature of the surface being analyzed. For vertical walls, in function of the $R a$ range, the equations listed below [14] are commonly applied:

$$
\begin{aligned}
& N u=0.59 \cdot R a^{\frac{1}{4}} \quad \text { for } 10^{4}<R a<10^{9} \\
& N u=0.10 \cdot R a^{\frac{1}{3}} \quad \text { for } 10^{9}<R a<10^{13}
\end{aligned}
$$

In literature, for vertical walls, another correlation can be found, which is independent of the number of $R a[14]$ :

$$
N u=\left\{0.825+\frac{0.387 R a^{\frac{1}{6}}}{\left[1+\left(\frac{0.492}{\operatorname{Pr}}\right)^{\frac{9}{16}}\right]^{\frac{8}{27}}}\right\}^{2} \quad \forall R a
$$

When mixed convection occurs, both natural and forced convection take on a certain relevance. In this case, the succeeding formula can be applied: 


$$
N u^{3}=N u_{\text {forced }}^{3}+N u_{\text {natural }}^{3}
$$

Based on laminar or turbulent regime, the $N u$ number for forced convection $\left(N u_{\text {forced }}\right)$ can be calculated through the following equations:

$$
N u_{\text {forced }}^{\text {LAM }}=0.664 \cdot \operatorname{Re}^{\frac{1}{2}} \cdot \operatorname{Pr}^{\frac{1}{3}} \quad \text { for } \operatorname{Re}<5 \cdot 10^{5} \text { and } \operatorname{Pr}>0.6
$$

$$
N u_{\text {forced }}^{\text {TURB }}=0.037 \cdot R e^{0.8} \cdot \operatorname{Pr}^{\frac{1}{3}} \quad \text { for } 5 \cdot 10^{5} \leq R e \leq 10^{7} \text { and } 0.6 \leq \operatorname{Pr} \leq 60
$$

where $P r$ is the Prandtl number. Consequently, the calculation of the $N u$ number allows to obtain $h_{c}$.

This methodological approach was applied considering different air velocity values in the hot chamber. Five small fans installed behind the baffle moved the air near the wall. The air speed was modified by progressively activating an increasing number of fans for achieving different environmental conditions. The air velocity in proximity of the wall was measured through a hot-wire anemometer. The first test was conducted keeping the ventilation system off. Three other tests were then conducted, reaching average values of air velocity equal to $0.06 \pm 0.01 \mathrm{~m} / \mathrm{s}, 0.09 \pm 0.01 \mathrm{~m} / \mathrm{s}$ and $0.13 \pm 0.01 \mathrm{~m} / \mathrm{s}$. The Holman's method [15] was applied to perform the uncertainty analysis. Figure 3 shows a simplified schematic depiction of the experimental setup.

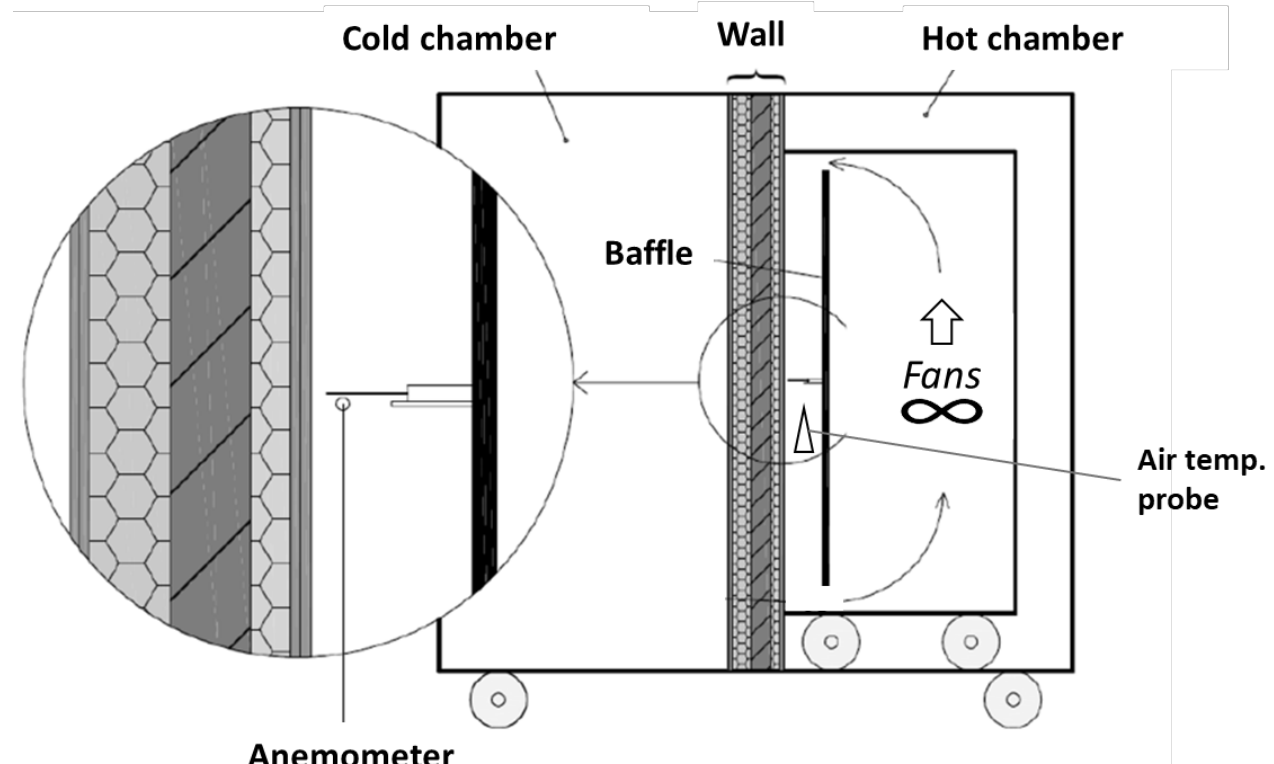

Fig. 3. Simplified GHB experimental set up.

\section{Results and discussion}

Measurements in the GHB were performed for a time during which steady-state internal environmental conditions (in terms of air temperatures and air speeds) occurred in the hot and cold chambers. Each of the tests was conducted considering 24 hours of experimental measurements, with a data acquisition rate of 10 minutes. Table 4 shows the air temperatures, the surface temperatures and the air velocities obtained during the measurement periods. 
Table 4. Air velocities, air and surface temperatures achieved in steady-state regimes.

\begin{tabular}{|c|c|c|c|c|c|}
\hline Test & $\begin{array}{c}\text { Average } \\
\text { air velocity } \\
{[\mathrm{m} / \mathrm{s}]}\end{array}$ & $\begin{array}{c}\text { Air temperature } \\
\text { hot chamber } \\
{\left[{ }^{\circ} \mathrm{C}\right]}\end{array}$ & $\begin{array}{c}\text { Sample surface } \\
\text { Temperature } \\
(\text { hot side) } \\
{\left[{ }^{\circ} \mathrm{C}\right]}\end{array}$ & $\begin{array}{c}\text { Baffle surface } \\
\text { temperature hot } \\
\text { chamber } \\
{\left[{ }^{\circ} \mathrm{C}\right]}\end{array}$ & $\begin{array}{c}\text { Air } \\
\text { temperature } \\
\text { cold chamber } \\
{\left[{ }^{\circ} \mathrm{C}\right]}\end{array}$ \\
\hline T0 & $<0.010$ & $20.13 \pm 0.09$ & $19.04 \pm 0.03$ & $20.18 \pm 0.07$ & $-0.16 \pm 0.21$ \\
\hline T1 & $0.064 \pm 0.010$ & $19.97 \pm 0.19$ & $18.80 \pm 0.01$ & $19.59 \pm 0.15$ & $-0.16 \pm 0.21$ \\
\hline T2 & $0.089 \pm 0.010$ & $20.00 \pm 0.31$ & $18.97 \pm 0.05$ & $19.90 \pm 0.39$ & $-0.16 \pm 0.21$ \\
\hline T3 & $0.135 \pm 0.010$ & $19.94 \pm 0.21$ & $18.95 \pm 0.01$ & $19.98 \pm 0.22$ & $-0.17 \pm 0.21$ \\
\hline
\end{tabular}

The dimensionless parameters approach was applied processing data related to air and surface temperatures, and air speeds. The so-called film temperatures ranging between $19.17^{\circ} \mathrm{C}$ and $19.58^{\circ} \mathrm{C}$ were found. A value equal to $1.516 \times 10^{-5} \mathrm{~m}^{2} / \mathrm{s}$ was used for the kinematic viscosity (suitable for film temperatures of about $20^{\circ} \mathrm{C}$ ), and a Prandtl number equal to 0.731 was applied [14]. Furthermore, considering the first test (called T0) during which the ventilation system was off, an air speed of $0.009 \mathrm{~m} / \mathrm{s}$ was assumed to calculate a Reynolds number greater than zero. Thus, the dimensionless numbers reported in Table 5 were found. It is worthy to observe that the Nusselt numbers were calculated applying both Eq. (7) and Eq. (9).

Table 5. Dimensionless numbers for the analyzed cases.

\begin{tabular}{|c|c|c|c|c|c|c|c|}
\hline Test & $G r$ & $R e$ & $A r$ & $R a$ & $\begin{array}{c}N u \\
\text { (natural) } \\
\text { Eq.(7) }\end{array}$ & $\begin{array}{c}N u \\
\text { (natural) } \\
\text { Eq.(9) }\end{array}$ & $\begin{array}{c}\text { Nu } \\
\text { (forced) } \\
\text { Eq.(11) }\end{array}$ \\
\hline T0 & $9.27 \times 10^{8}$ & $1.07 \times 10^{3}$ & 812.01 & $6.78 \times 10^{8}$ & 95.20 & 109.43 & - \\
\hline T1 & $9.96 \times 10^{8}$ & $7.62 \times 10^{3}$ & 17.18 & $7.28 \times 10^{8}$ & 96.92 & 111.87 & - \\
\hline T2 & $8.81 \times 10^{8}$ & $1.05 \times 10^{4}$ & 7.95 & $6.44 \times 10^{8}$ & 93.98 & 107.71 & 61.35 \\
\hline T3 & $8.42 \times 10^{8}$ & $1.60 \times 10^{4}$ & 3.28 & $6.16 \times 10^{8}$ & 92.93 & 106.24 & 75.70 \\
\hline
\end{tabular}

It is worthy to notice that in T0 and T1 the convection is merely natural, with an $\mathrm{Ar}$ number much greater than 10. Differently, in T1 and T2, mixed convection conditions occurred, with an $A r$ number between 0.7 and 10. The convective heat transfer coefficients shown in Figure 4 were obtained from the $N u$ numbers. In order to obtain correlations for $h_{c}$ as a function of the air velocity near the wall, two trend lines (both with an $\mathrm{R}^{2}$ greater than 0.9) have been drawn for data obtained through Eq. (7) and Eq. (9). 


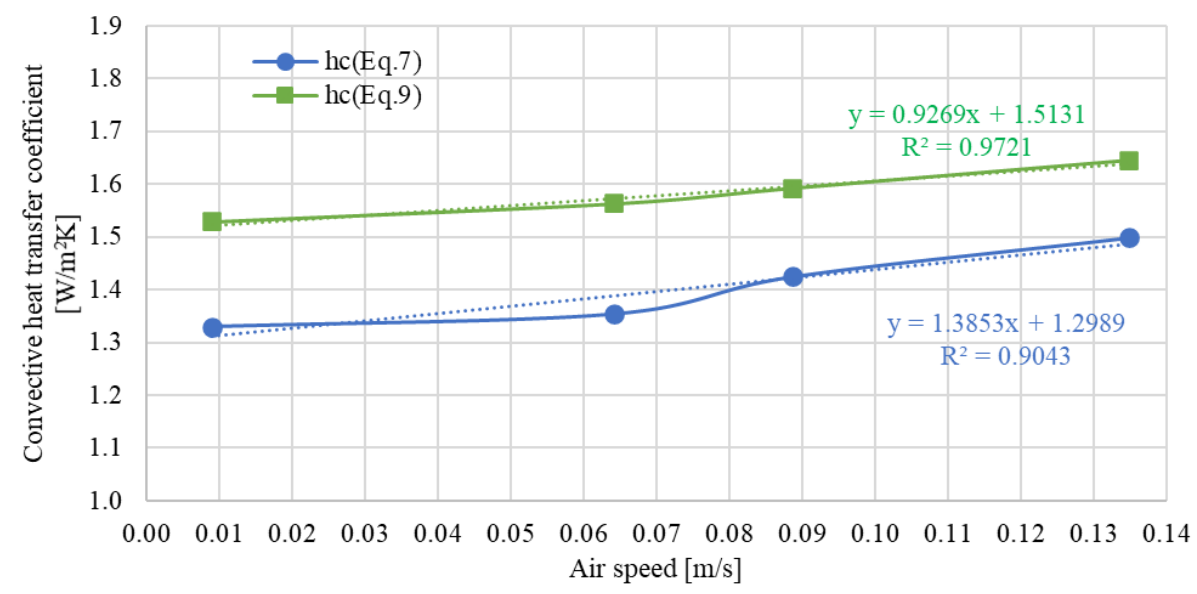

Fig. 4. Convective heat transfer coefficients in function of air speeds.

Comparing the convective coefficients obtained through the two correlations and those achieved by the dimensionless numbers' analysis, it is possible to notice that the experimental data are well described by the correlations, with a more evident difference only in the T1 test. Starting from the results shown in Figure 4, the following correlations were found applying Eq. (7) and Eq. (9): $h_{c(E q 7)}=1.3853 v+1.2989$ and $h_{c(E q 9)}=0.9269 v+1.5131$.

Table 6 shows the comparison between the convective coefficients obtained through Eq. (7) and Eq. (9), and from the ISO 6946 standard. Considering the $h_{c}$ found by means of Eq. (7) and the standard, it is possible to observe percentage differences on average between $46.82 \%$ and $-40.04 \%$. On the other hand, considering the $h_{c}$ found by means of Eq. (9) and the standard, percentage variations range on average from $-38.87 \%$ to $-34.21 \%$. Finally, comparing the results obtained from Eq. (7) and Eq. (9), it is possible to observe $h_{c}$ values higher when Eq. (9) is used, with an average percentage difference equal to about $+13 \%$.

So, it is possible to conclude that the convective heat transfer coefficients found through the experimental data acquired in the GHB and the post-processing approach are always lower than that proposed by ISO 6946.

Table 6. Convective coefficients found through Eq.(7), Eq.(9) and from ISO 6946.

\begin{tabular}{|c|c|c|c|}
\hline Test & $\begin{array}{c}h_{c} \text { (Eq.7) } \\
{\left[\mathrm{W} / \mathrm{m}^{2} \mathrm{~K}\right]}\end{array}$ & $\begin{array}{c}h_{c} \text { (Eq.9) } \\
{\left[\mathrm{W} / \mathrm{m}^{2} \mathrm{~K}\right]}\end{array}$ & $\begin{array}{c}h_{c} \text { ISO 6946 } \\
{\left[\mathrm{W} / \mathrm{m}^{2} \mathrm{~K}\right]}\end{array}$ \\
\hline $\mathrm{T} 0$ & $1.33 \pm 0.03$ & $1.53 \pm 0.05$ & 2.50 \\
\hline $\mathrm{T} 1$ & $1.35 \pm 0.06$ & $1.56 \pm 0.10$ & 2.50 \\
\hline $\mathrm{T} 2$ & $1.42 \pm 0.10$ & $1.59 \pm 0.13$ & 2.50 \\
\hline $\mathrm{T} 3$ & $1.50 \pm 0.05$ & $1.64 \pm 0.07$ & 2.50 \\
\hline
\end{tabular}

\section{Conclusions}

In this research, convective heat transfers phenomena were investigated by means of a GHB, setting up an experimental system made up of air and surface temperature sensors and a hotwire anemometer. All these sensors were installed in the GHB, to assess the heat transfer phenomena of a typical indoor environment during winter. A forced convection system characterized by five fans was used to indirectly move the air near the wall, thus imposing different air speed rates. The method based on the dimensionless numbers was applied for identifying a correlation between convective coefficients and air speeds near the wall. With 
this purpose, two different correlations were applied. The results were also compared with the value suggested by the standard ISO 6946.

Natural convection conditions were identified for T0 and T1 tests, during which the ventilation system was off, and the air speed did not exceed the average value of $0.064 \pm$ $0.010 \mathrm{~m} / \mathrm{s}$. Differently, mixed convection occurred during T2 and T3 tests. The experimental approach allowed to find two correlations, both characterized by $\mathrm{R}^{2}>0.9$, able to identify the correlations between $h_{c}$ and air velocity. Convective coefficient values much lower than that proposed by the ISO 6946 were found, with percentage variations ranging from $-46.82 \%$ to $-34.21 \%$.

It is worthy to observe that these results need to be further investigated using data deriving from much more sensors installed along the vertical profile of the wall. In this way, different values of the convective coefficients could be obtained to investigate the differences in terms of the vertical profile of the coefficient $h_{c}$.

\section{References}

1. G. Desogus, S. Mura, R. Ricciu, Comparing different approaches to in situ measurement of building components thermal resistance, Energ Build 43, 2613 (2011).

2. Oral GK, Yilmaz Z, The limit $U$ values for building envelope related to building form in temperate and cold climatic zones. Build Environ 37, 1173-80 (2002).

3. Prada A, Cappelletti F, Baggio P, Gasparella A, On the effect of material uncertainties in envelope heat transfer simulations. Energy Build 71, 53-60 (2014).

4. T. de Rubeis, I. Nardi, M. Muttillo, D. Paoletti, The restoration of severely damaged churches - Implications and opportunities on cultural heritage conservation, thermal comfort and energy efficiency, J Cult Herit 43, 186-203 (2020).

5. ISO 6946 - Building components and building elements - Thermal resistance and thermal transmittance - Calculation methods. International Standard, Brussels, 2017.

6. L. Evangelisti, C. Guattari, F. Asdrubali, Comparison between heat-flow meter and AirSurface Temperature Ratio techniques for assembled panels thermal characterization, Energy Build 203, 109441 (2019).

7. L. Evangelisti, C. Guattari, T. de Rubeis, Preliminary analysis of the influence of environmental boundary conditions on convective heat transfer coefficients, J Phys Conf Ser 1868, 012024 (2021).

8. A.A. Lechowska, J.A. Schnotale, G. Baldinelli, Window frame thermal transmittance improvements without frame geometry variations: An experimentally validated CFD analysis. Energy and Buildings 145,188-199 (2017).

9. K. Martin, A. Campos-Celador, C. Escudero, I. Gómez, J.M. Sala, Analysis of a thermal bridge in a guarded hot box testing facility. Energy and Buildings 50, 139-149 (2012).

10. T. de Rubeis, M. Muttillo, I. Nardi, L. Pantoli, V. Stornelli, D. Ambrosini, Integrated Measuring and Control System for Thermal Analysis of Buildings Components in Hot Box Experiments, Energies 12, 2053 (2019).

11. T. de Rubeis, I. Nardi, M. Muttillo, Development of a low-cost temperature data monitoring. An upgrade for hot box apparatus, J Phys Conf Ser 923, 012039 (2017).

12. UNI EN ISO 8990. Thermal Insulation-Determination of Steady-State Thermal Transmission Properties - Calibrated and Guarded Hot Box; International Standard Organization: Geneva, Switzerland, 1999.

13. Sami A. Al-Sanea, M.F. Zedan, M.B. Al-Harbi, Heat transfer characteristics in airconditioned rooms using mixing air-distribution system under mixed convection conditions, International Journal of Thermal Sciences 59, 247-259 (2012).

14. T.L. Bergman, A.S. Lavine, F.P. Incropera, D.P. Dewitt, Fundamentals of Heat and Mass Transfer, John Wiley \& Sons, 2017, ISBN 13 978-0470-50197-9. 
15. J.P. Holman, Experimental methods for engineers, 8th ed.; McGraw-Hill series in mechanical engineering; ISBN-13: 978-0-07-352930-1. 